\title{
NOTES ON SHORT EXPERIMENTS BEARING ON THE RELATION OF LARVAL TO ADULT LEGS.
}

BY ALEC. ARSENE GIRAULT, WASHINGTON, D.C. \section{Gonin.}

"The real relations of the adult legs to the larval legs are thus shown by

'If we carefully strip off the skin of a caterpillar near the time of pupation (Fig. 608), we see that the extremity only of the legs of the imago is drawn out of the larval legs; the other parts are pressed against each side of the thorax: near the ventral line a small pad represents the coxa and the trochanter; the femur and the tibia are distinctly recognizable, but soldered to each other and only separated by a slight furrow; they form by their union a very acute knee or bend. The femur is movable on the pad-like coxa, the tibia continues without precise limits with the extremity concealed in the larval legs. The three divisions of the latter do not appear to have any relation to the five joints of the perfect state. Under the microscope the rudiment appears very strongly plaited at the level of the tarsus, much less so in the other regions. A large trachea penetrates into the femur with some capillaries; reaching the knee it bends into the tibia at a sharp curve, but does not become truly sinuous in approaching the extremity. It is then the tarsus especially which is susceptible of elongation; it may, on being withdrawn, give rise to the illusion that the whole organ is disengaged from the larval leg.

Even when wa cat off the limb of the caterpillar at its base, we only remove the tarsus of the imago; the femur and the tibia remain intact. From an evident homology Réaumur has erroneously concluded that there is an identity. His opinion, classical up to this day, that the limb of the butterfly is entirely contained in the leg of the caterpillar, has been found to be inexact and should be abandoned." "a

From the foregoing quotation, the following short experiments performed on the larvæ of Heliothis olssoleta Fabricius, ${ }^{b}$ are easily understood.

On the 2oth of June at Paris, Texas, ten (10) full-grown larvæ of this insect were taken from ears of corn and placed on fresh soil in the laboratcry. They were ready to enter the soil. The anterior legs of each were immediately cut

a Packard. A Text-book of Entomology 1898 pp 654-655.

b Formerly Heliothis armiger Hübner. 
off with sharp scissors, taking care, during the operation, to remove the articulated joints only. The larvæ were then allowed to enter the earth, which six of them successfully accomplished during the following night. The remaining four were found dead and were removed.

From these six larva, three moths appeared on July 7 th, following. Of the three, two had perfect legs. But the other had two of the apical joints of its dextral foreleg missin;, the third and last joint bearing the usual tursal claws. The conclusion to be drawn is obviously indicated by reference to the lines quoted.

Other experiments performed were failures because of the corresponding moths not issuing. The pupa of a larva whose legs had been amputated at the origin of the articulated joints, was dissected when some days old, and the half formed moth found with perfectly formed limbs.

Two full-grown larva were transferred to soil in a large glass jar and treated as formerly, but in addition to the articulated . joints, a portion of the large lobe of the body to which the legs are appended was also removed, doubtless injuring the so called histoblast. When cut, both of them jumped violently and a stream of dark liquid was ejected from the mouth. They immediately crawled off, however, when liberated seemingly not missing the pair of legs. The wounds bled for a short while, but healed the next day, then showing as large blackened scars. Although feeding voraciously, and apparently ready to pupate, both suddenly declined and died, and for lack of time the experiment was not repeated.

The percentage of moths successfully emerging from larvæ thus mutilated is very small, and it is vary nezessary to use larger lots in experiments such as these. 

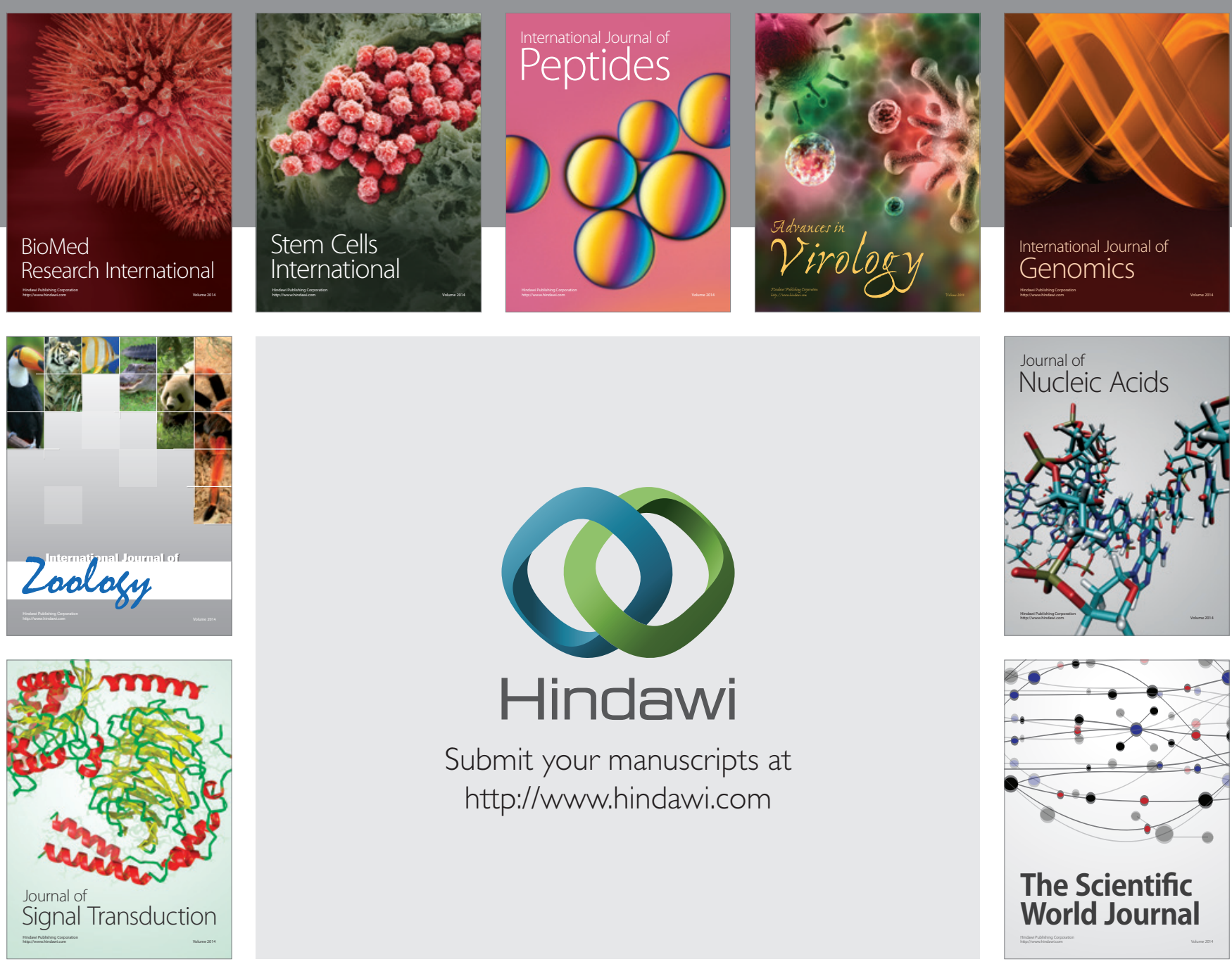

Submit your manuscripts at

http://www.hindawi.com
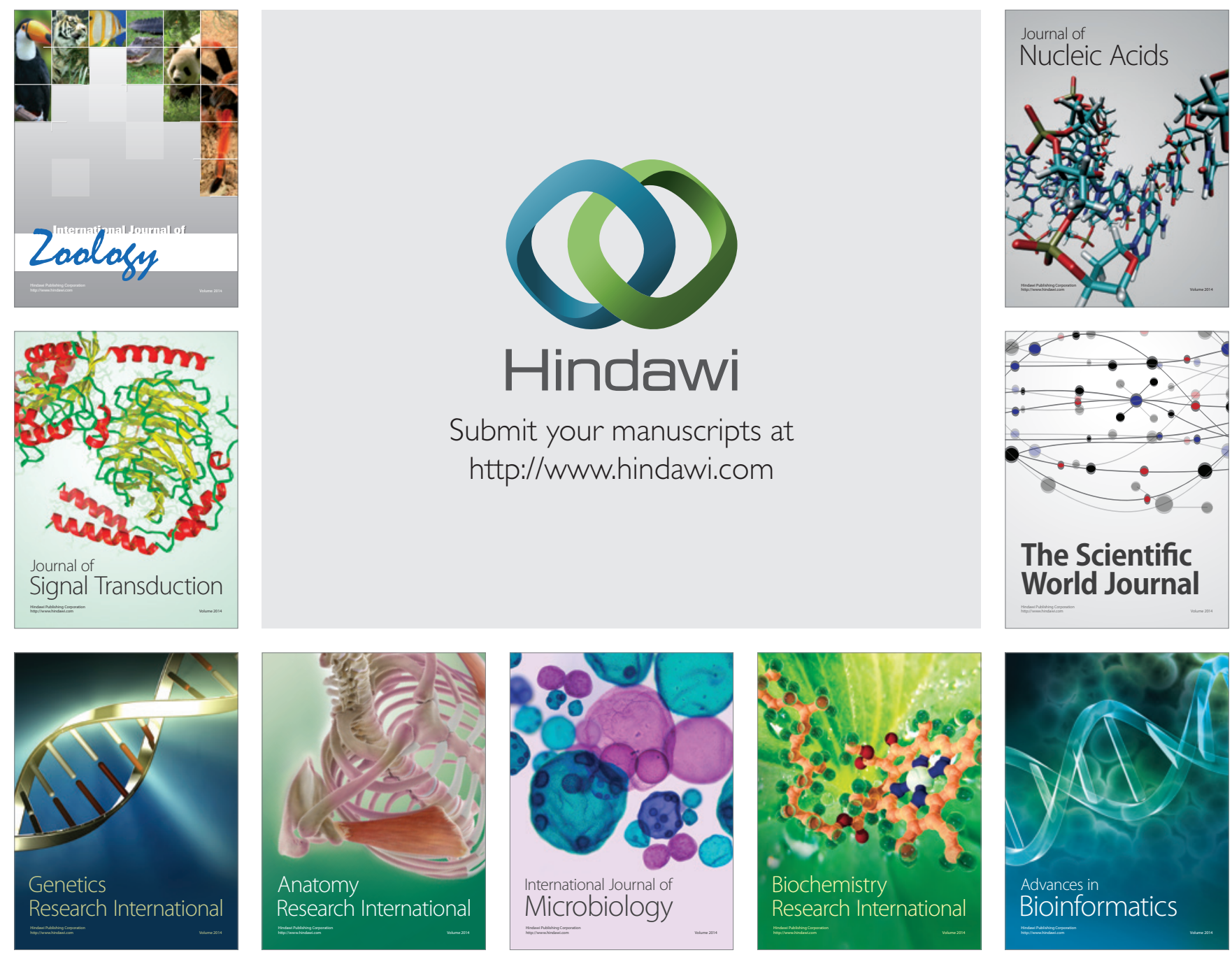

The Scientific World Journal
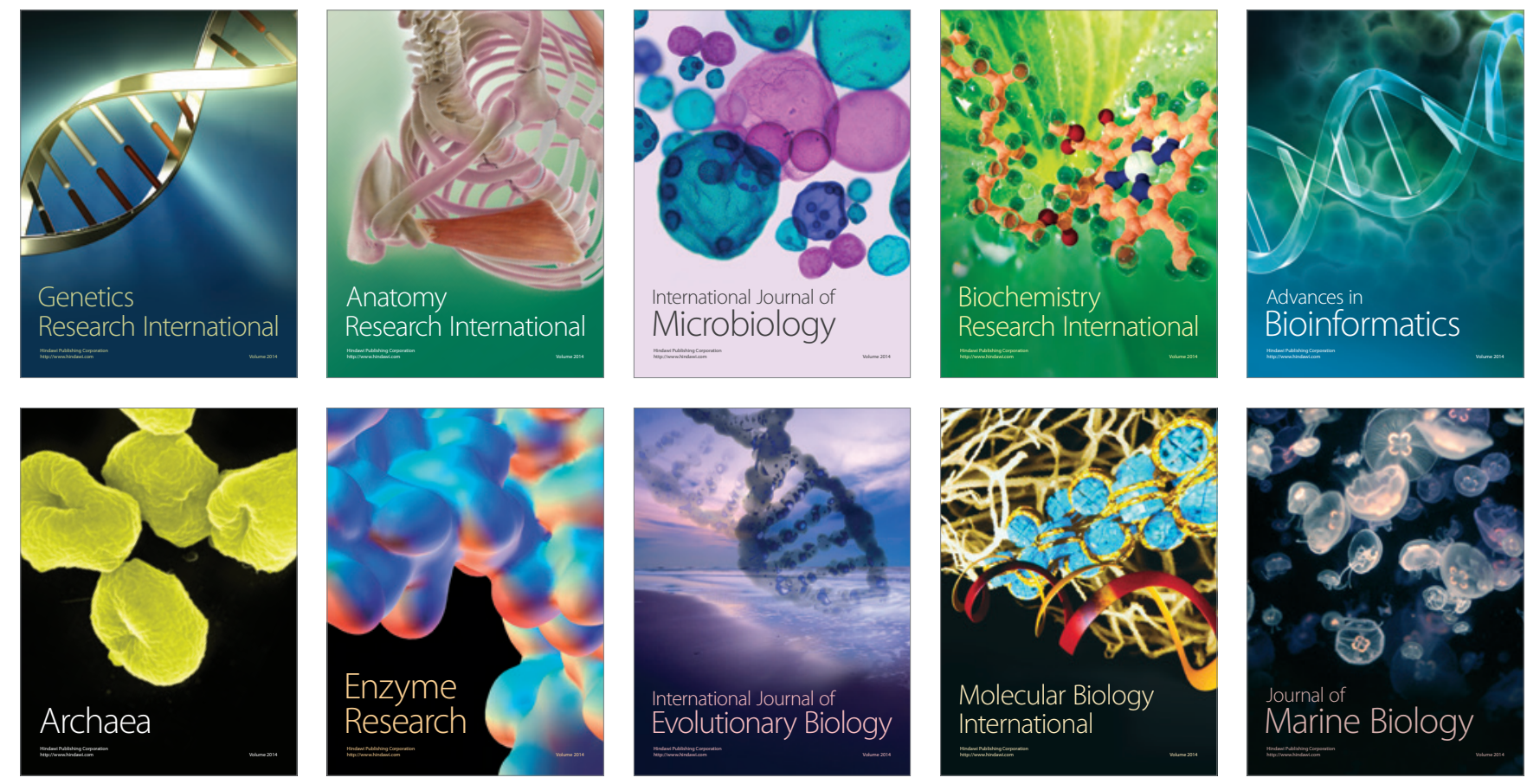